\title{
Modelling the ecological niche of hookworm in Brazil based on climate
}

\author{
Ntombi B. Mudenda ${ }^{1}$, John B. Malone ${ }^{1}$, Michael T. Kearney ${ }^{1}$, Paula D. Mischler ${ }^{1}$, Prixia del \\ Mar Nieto ${ }^{1}$, Jennifer C. McCarroll ${ }^{1}$, Penelope Vounatsou ${ }^{2,3}$ \\ ${ }^{1}$ Department of Pathobiological Sciences, School of Veterinary Medicine, Louisiana State University, Baton \\ Rouge, LA 70803, USA; ${ }^{2}$ Department of Epidemiology and Public Health, Swiss Tropical and Public Health \\ Institute, P.O. Box, CH-4002, 4051 Basel, Switzerland; ${ }^{3}$ University of Basel, P.O. Box, CH-4003 Basel, \\ Switzerland
}

\begin{abstract}
The distribution of hookworm in schistosomiasis-endemic areas in Brazil was mapped based on climate suitability. Known biological requirements of hookworm were fitted to data in a monthly long-term normal climate grid $(18 \mathrm{x} 18 \mathrm{~km})$ using geographical information systems. Hookworm risk models were produced using the growing degree day (GDD) water budget (WB) concept. A moisture-adjusted model (MA-GDD) was developed based on accumulation of monthly temperatures above a base temperature of $15^{\circ} \mathrm{C}$ (below which there is no lifecycle progression of Necator americanus) conditional on concurrent monthly values (rain/potential, evapotranspiration) of over 0.4 . A second model, designated the gradient index, was calculated based on the monthly accumulation of the product of GDD and monthly WB values (GDD x WB). Both parameters had a significant positive correlation to hookworm prevalence. In the northeastern part of Brazil (the Caatinga), low hookworm prevalence was due to low soil moisture content, while the low prevalence in southern Brazil was related to low mean monthly temperatures. Both environmental temperature and soil moisture content were found to be important parameters for predicting the prevalence of $N$. americanus.
\end{abstract}

Keywords: hookworm, Necator americanus, risk models, growing degree days, water budget, geographical information systems, Brazil.

\section{Introduction}

Hookworm infection is a worldwide public health problem particularly in the parts of the world where poverty levels are high such as the developing countries of Asia, Africa and Latin America where an estimated 740 million people are infected (WHO, 2011). Of great concern in hookworm infection is the resultant iron deficiency anaemia due to intestinal blood loss, especially in children and women of reproductive age and also the reduced cognitive ability of infected children (Stoltzfus et al., 1996; Brooker et al., 2006b; Hotez, 2008). Brazil launched a Schistosomiasis Control Program (SCP) in 1976, which is an active decentralized, federal programme in the endemic areas (Amaral et al., 2006). The Kato-Katz technique (Katz et al., 1972), utilized in this programme for the detection of Schistosoma mansoni eggs also shows the pres-

Ntombi B. Mudenda,

Department of Pathobiological Sciences

School of Veterinary Medicine, Louisiana State University

Baton Rouge, LA 70803, USA

Tel. +1 225221 5536; Fax +1 2255789701

E-mail: nmuden1@tigers.lsu.edu ence of many other helminth eggs and several studies have demonstrated that co-infection of Schistosoma spp. and soil-transmitted helminths is common, including hookworm, Ascaris lumbricoides and Trichuris trichiura (Booth and Bundy, 1992; Booth et al., 2003; Fleming et al., 2006).

Human hookworm infections are caused by Necator americanus or Ancylostoma duodenale. Studies in Brazil have shown that N. americanus is the predominant hookworm species (Geiger et al., 2004; Brooker et al., 2006b; Fleming et al., 2006). The eggs of this species do not develop in temperatures below $15^{\circ} \mathrm{C}$ and the larvae prefer shady, moist areas with temperatures at or above $30{ }^{\circ} \mathrm{C}$ but are killed above $45^{\circ} \mathrm{C}$ (Udonsi and Atata, 1987). N. americanus fares best in sandy loam soils where the worms have been shown to migrate vertically to depths down to $1 \mathrm{~m}$ (Palmer and Reeder, 2001) but most specimens remain in the top $5 \mathrm{~cm}$ layer as long as the soil is moist (Udonsi et al., 1980). They have been shown to survive for up to six weeks although the yield becomes progressively lower over time (Svensson, 1925; Udonsi and Atata, 1987). Beaver (1953) found that live larval recovery from soil after one week was less than 40\% and others (Croll and Matthews, 1973) 
reported similar findings using A. tubaeforme, showing that the larval activity levels reduced by more than $50 \%$ in the same period of time. Other studies have shown that larvae survive for longer periods at lower temperatures (between $20-25^{\circ} \mathrm{C}$ ) than at temperatures above $30{ }^{\circ} \mathrm{C}$ (Svensson, 1925; Udonsi and Atata, 1987; Udonsi, 1988; Brooker et al., 2006b). Brooker et al. (2006b) reported that the life expectancy of the free living infective stage of hookworms is 3 10 days and that of the adult parasite, 3-4 years. When potential infectivity was assessed, it was found that larvae lost the ability to penetrate fresh rabbit skin after 11-15 days (Udonsi, 1988), apparently due to exhaustion of the worm energy stores.

This evidence suggests that infectivity of hookworms in the environment is relatively short, on the order of a few weeks on average, and that the life cycle survival strategy of $N$. americanus is highly dependent on the 3-4 year longevity of adult worms in infected human hosts. As a principle of hookworm control, focus on removal of adult worms may be an effective strategy, since free-living, infectious, third-stage larvae $\left(\mathrm{L}_{3}\right)$ is short lived without replenishment by a stable population of egg shedding adult worms. According to World Health Organization (WHO) guidelines for control of hookworm, prevalence of over $50 \%$ is considered high, $20 \%$ to $50 \%$ moderate and $<20 \%$ low. These prevalence rates guide recommended control measures and resources devoted to hookworm infection (WHO, 2011).

Remote sensing and geographical information systems (GIS) have been used to map distribution of parasites and diseases as well as to develop prediction models for disease distributions in many regions of the world. However, it is important to understand the environmental properties that contribute to the ecological niche of a particular parasite or vector to be able to predict the distribution (Malone, 2005). Risk maps based on known biological requirements and climatic variables have been employed for a number of diseases, including malaria (Thomson et al., 1997; Yang et al., 2010), schistosomiasis (Lindsay and Thomas, 1999; Malone et al., 2001), filariasis (Lindsay and Thomas, 1999), leishmaniasis (Nieto et al., 2006; Salahi-Moghaddam et al., 2010), among others (Bergquist and Rinaldi, 2010). Such models have proven to be useful for formulating disease control programmes in various parts of the world.

The concept of growing degree days (GDD) and water budget (WB) provides a measure of thermalhydrological regime in relation to species-specific knowledge of base temperature (below which no development occurs), optimal temperature range for development, lethal upper limiting temperatures and limiting moisture regime in the context of the extrinsic thermal units (GDD-WB) that must accumulate for a parasite-vector system to complete one or more generations. Specifically, the GDD-WB concept has been used successfully to generate predictive models of fascioliasis in the United States, Ethiopia, Ecuador and southern Brazil (Malone et al., 1987, 2001; Fuentes et al., 2005; Dutra et al., 2010; Valencia-López et al., 2012), schistosomiasis in the People's Republic of China and East Africa (Zhou et al., 2001; Malone, 2005) and visceral leishmaniasis in Bahia, Brazil (Nieto et al., 2006).

For hookworm, GIS and remote sensing methodologies have been used to study the spatial distribution of the parasite and produce risk prediction models for the African continent (Brooker et al., 2006a), Kwazulu Natal in South Africa (Mabaso et al., 2003), and Côte d'Ivoire (Raso et al., 2006). However, according to the literature consulted, risk maps using biological data and climate regime have not been developed for hookworm infection in Brazil on a national scale.

The study reported here used hookworm prevalence data concurrently reported as part of surveillance and control programmes for $S$. mansoni-endemic areas in Brazil from 2000-2009. National scale risk maps on the distribution of hookworm infection were developed by applying known biological information on $N$. americanus to the climate envelope of conditions suitable for the survival, propagation and transmission of this hookworm species.

\section{Materials and methods}

Brazil, has a mainly tropical climate with five major ecological zones (FAO, 2001). The hookworm prevalence data used were acquired from the Brazilian national notifiable diseases information system (Sistema Nacional de Agravos de Notificação SINAN) and contained the proportion positive for hookworm at the municipality level from 2000 to 2009. Municipalities where less than 100 people were examined were excluded, resulting in a total of 980 municipality data points. Using these criteria, 30 municipality points were excluded.

The mapping and modelling software used was ArcGIS 9.3 (ESRI, Redlands, CA, USA). Boundary map shape files for political units in Brazil were obtained from a South American Minimum Medical 
GIS database resource (Malone et al., 2007b) using data downloaded from the DIVA-GIS website (http://diva.riu.cip.cgiar.org/index.php). The climate data was a long-term-normal (LTN) climate grid (18 x $18 \mathrm{~km}$ cell size) of South America (Corbett, 2005). Each cell contained monthly long-term, normal, average data on rainfall, maximum daily temperature, minimum daily temperature, potential evapotranspiration and the ratio of precipitation to potential evapotranspiration (PPE), also known as water budget.

The administrative boundary map of Brazil, prevalence data points, and climate grid data were imported into ArcGIS and re-projected to ensure that the coordinate systems were the same. The prevalence data point map and the climate grid attribute tables were joined using the polygon-to-point join function to produce a composite layer for GDD-WB analysis and calculation of the potential number of transmission cycles possible per year at positive municipalities. The values derived were used to extrapolate the model by calculating model variables for the entire national municipality map, including municipalities where data were absent, using the layer properties/symbology function of ArcGIS.

\section{Construction of the MA-GDD and GDDxWB models}

GDD for hookworm were calculated by the field calculator function of ArcMap using a base temperature of $15^{\circ} \mathrm{C}$ for each month as follows (Malone et al., 2007a):

(Mean monthly temperature - 15) x the number of days in a particular month

For annual potential GGD, the monthly GDD's were added together for each municipality survey point using the field calculator function of ArcGIS.

\section{MA-GDD model}

The accumulated annual GDD was calculated after excluding the GDD accumulated in the dry months (identified as a month when the water budget was less than 0.4$)$. Soil saturation or "field capacity" is reached at a value of 1.0 and monthly values above 1.0 have surplus/runoff water. This cut-off was used because the prevalence of hookworm in the 2000-2009 hookworm survey database from Brazil was found to be absent or low $(<5 \%)$ at municipality points with water budgets $<0.4$.
Gradient index model (GDDxWB)

Potential GDD and WB for each data point were multiplied to develop an index in which the temperature associated development of the hookworm was related to a moisture gradient (water budget). The gradient index model was calculated for each month. The average annual value was calculated by summing the monthly mean GDDxWB values.

\section{Calculation of transmission time and annual transmis- sion cycles}

The mean transmission time was defined as the time spent in the free-living state of the hookworm, from deposition of eggs into the environment to infection of the host by viable $\mathrm{L}_{3}$. It was calculated based on literature reports (Svensson, 1925; Beaver, 1953; Udonsi, 1988) as follows:

\section{Mean transmission time $=$ the development time \\ from egg to infective larva (14 days) + time as active infective larva (14 days)}

Transmission cycle GDD $=$ (mean transmission time) $x$ daily GDD

Potential transmission cycles per year values were calculated based on the number of potential transmission cycles per annum for hookworm at all survey data points as follows:

\section{Annual MA-GDD/transmission cycle GDD}

Models were then developed using water budget, GDD and the transmission cycle values to predict potential risk zones for hookworm transmission in Brazil.

\section{Model validation}

A literature search was conducted to review reports on independent surveys for prevalence of hookworm and other soil-transmitted helminths that had been carried out in Brazil. These results were used to validate the MA-GDD and GDDxWB models.

The Statistical Analysis Software (SAS ${ }^{\circledR}$, Cary, NC, USA), was used to determine correlations between prevalence of hookworm and the variables MA-GDD and GDDxWB using Pearson correlation. The Student's t-test (assuming unequal variances) was used to determine if there was a significant difference 
between the annual potential GDD and the MA-GDD or between GDD and GDDxWB. The t-test was also used to compare the MA-GDD means in the different prevalence categories (low, medium and high) as well as the GDDxWB index means in the different prevalence categories. Data points with prevalence less than $1 \%$ were excluded for statistical analysis resulting in 562 data points of the 980 municipalities with data. Regression was used to determine the relationship between mean transmission cycles and the GDDxWB index.

\section{Results}

The mean prevalence of hookworm among the municipalities in the data set was $5.0 \%$ (range $=0$ $70.2 \%$; standard deviation $(\mathrm{SD})=8.9 \%$ ). The prevalence distribution at 980 municipality sites is shown in Table 1, categorized as very low, low, medium and high prevalence.

There was a significant difference by Student's t-test between annual GDD and MA-GDD values $(\mathrm{P}<0.001)$ and between annual GDD and GDDxWB index $(\mathrm{P}<0.001)$. This result showed the importance of the moisture variable, as measured by water budget, and that the GDD and MA-GDD or GDDxWB variables could be used independently in the modelling process. The Pearson correlation coefficients between hookworm prevalence and MA-GDD and between hookworm prevalence and GDDxWB index were 0.25 $(\mathrm{P}<0.001)$ and $0.38(\mathrm{P}<0.001)$ respectively. The MAGDD and GDDxWB means in the three categories of prevalence (low, medium, high) were all significantly different $(\mathrm{P}<0.001)$ (i.e. the MA-GDD mean in the low prevalence group was significantly different from that in the medium and high prevalence groups and that between the medium prevalence group was different from the high prevalence group). However, the MA-GDD range in the high prevalence group (mean = $2,197$; range $=1,176-3,158)$ overlapped with the medium prevalence group range (mean $=1,990$; range $=1,191-3,247)$.

Table 1. Distribution of hookworm prevalence among the 980 municipalities surveyed.

\begin{tabular}{lcc}
\hline Category & $\begin{array}{c}\text { Hookworm } \\
\text { prevalence }(\%)\end{array}$ & $\begin{array}{c}\text { Number } \\
\text { of municipalities }\end{array}$ \\
\hline Very Low & $<1$ & 418 \\
Low & $1-4.9$ & 298 \\
Medium & $5-19.9$ & 189 \\
High & $>20$ & 75 \\
\hline
\end{tabular}

The relationship between the mean transmission cycles and GDDxWB index was determined by the formula $\mathrm{y}=251.6+163.6 \mathrm{x}+12.5 \mathrm{x}^{2}$, where $\mathrm{x}$ is mean transmission cycles and y is GDDxWB. One transmission cycle therefore translates to a 428 GDDxWB index value and 14 transmission cycles translate to a 4,992 GDDxWB index value.

The MA-GDD model (Fig. 1) and the GDDxWB model (Fig. 2) both predicted a low hookworm prevalence of $<5 \%$ in the Caatinga region (characterized by deserts and xeric shrubs) and in the southern region of Brazil. The MA-GDD model (Fig. 3) showed that where the transmission cycles were less than 5 per year, or more than 14 per year, the hookworm prevalence was low $(<5 \%)$. The GDDxWB index model showed a low end cut off at 1,300 (Fig. 4) below which the prevalence of hookworm fell below $5 \%$.

Thirty independent reports published between 1990 and 2010 by various authors were reviewed and used for the purpose of validating the climate risk prediction models developed in the current study (Table 2). These articles covered 16 states out of Brazil's 26 states. The prevalence of hookworm in the 30 literature reports ranged from 0 to $80.2 \%$ with a mean of $20.3 \%($ SD $=22.3 \%)$. The number of people examined ranged from 54 to 13,279 . Sampled populations ranged from studies on schoolchildren to studies on whole communities. While the 30 data points available from literature were limited there was a general agreement of survey data to the predicted GDDxWB index risk map (Fig. 5).

\section{Discussion}

In the current study on the development of ecological niche models for hookworm in Brazil, there was a need for a standard measure of the developmental suitability of a site for propagation and transmission of the parasite based on climate and known biological parameters that can distinguish low, moderate and high risk conditions for hookworm disease.

Temperature and moisture environmental parameters are fundamental determinants of the distribution range and abundance of free-living species (Andrewartha and Birch, 1954). The GDD-WB concept provides a measure of thermal-hydrological regime in relation to species-specific knowledge of base temperature (below which no development occurs), optimal temperature for development, upper lethal limiting temperatures and limiting moisture regime in the context of the thermal units that must accumulate for a parasite-vector system to complete 


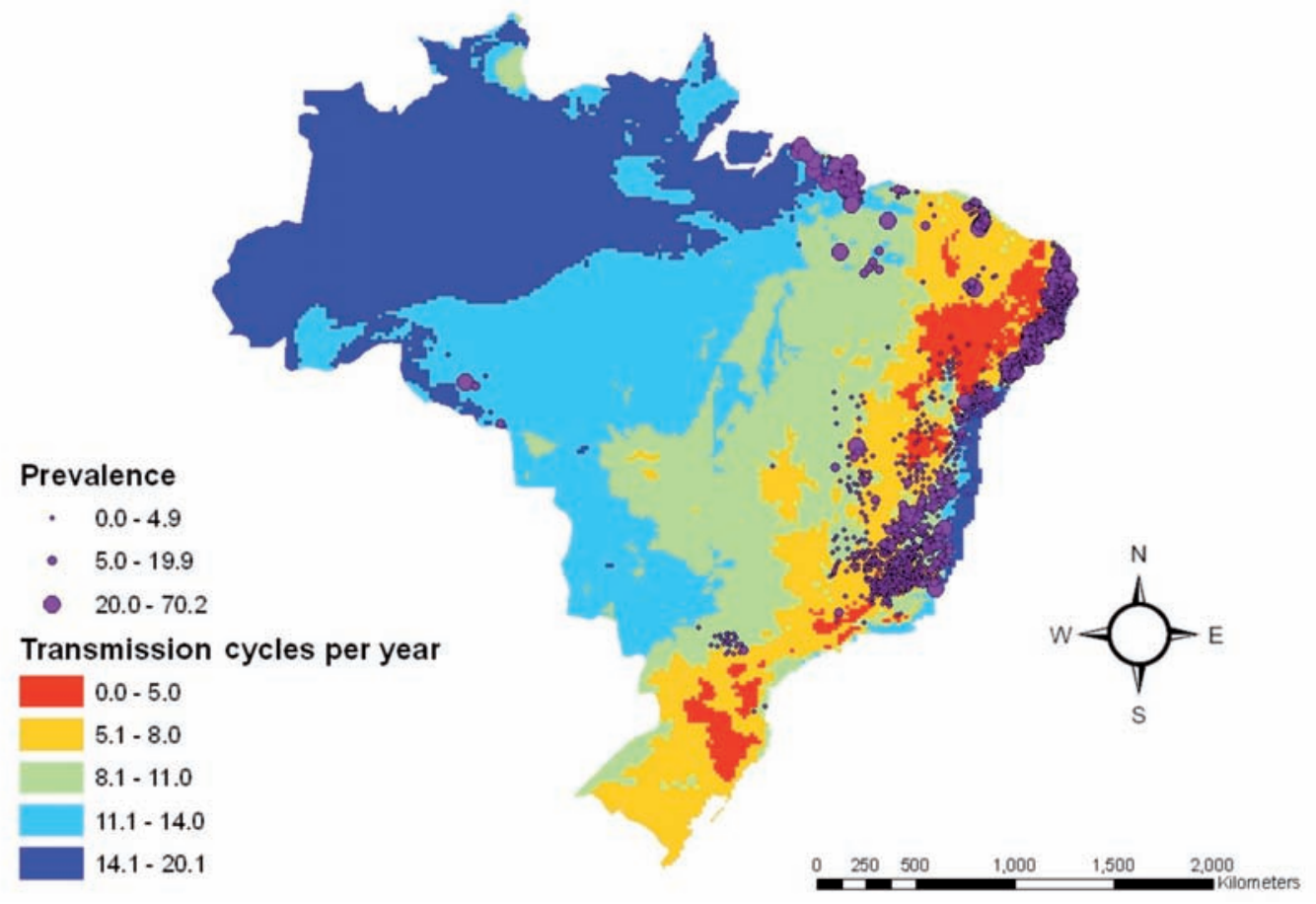

Fig. 1. Risk model for hookworm based on the MA-GDD index. Moderate to high prevalence is most likely to occur between five and 14 transmission cycles per year (yellow to light blue). Areas with less than five transmission cycles per year (red) are prohibitive to hookworm transmission. Graduated circles (purple) represent municipality data points of low (small circle) to high (large circle) prevalence.

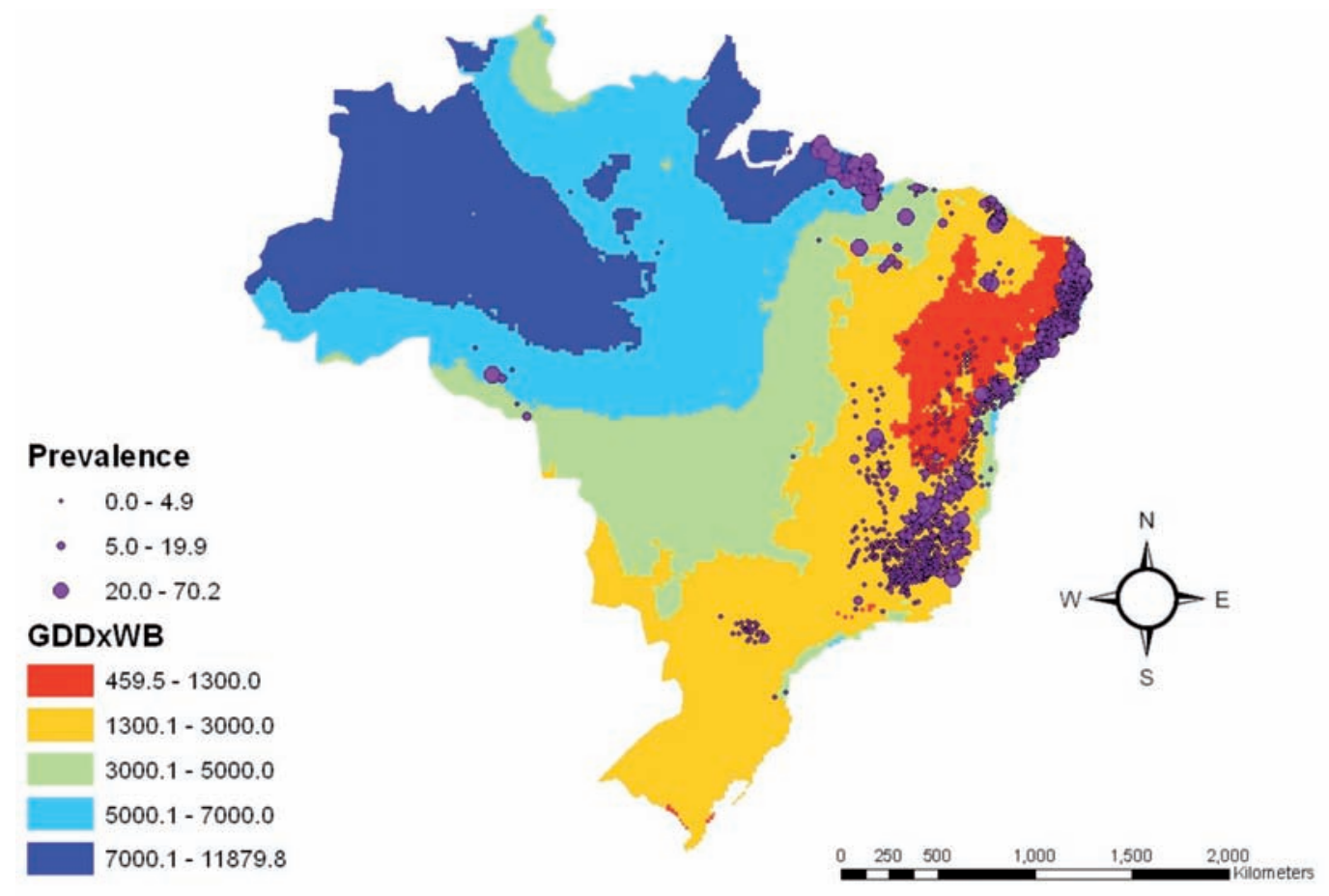

Fig. 2. Hookworm prevalence risk model based on the GDDxWB index. Areas of low (red) to high (dark blue) prevalence risk are shown. Graduated circles (purple) represent municipality data points of low (small circle) to high (large circle) prevalence. 


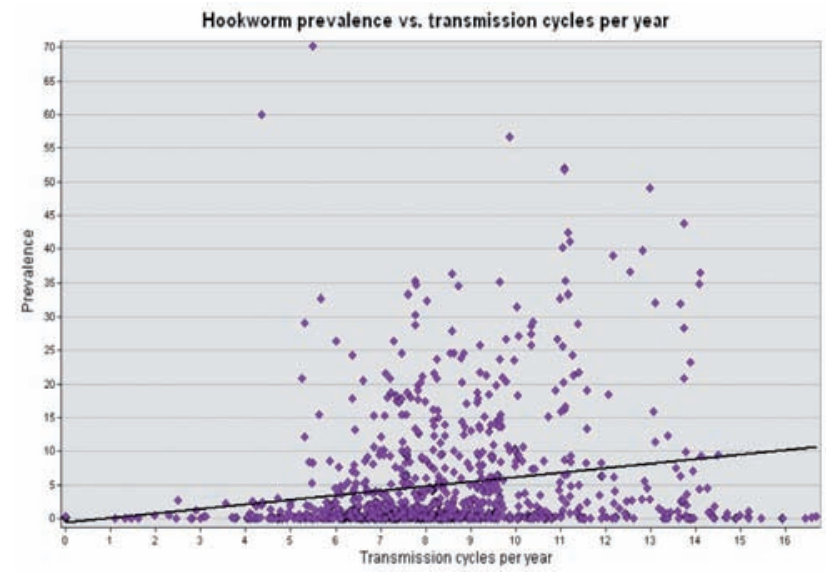

Fig. 3. Scatter plot of hookworm prevalence from municipality data points against transmission cycles per year. A lower end cut-off at five transmission cycles, below which the prevalence is less than 5\% and an upper end cut-off at about 14 transmission cycles, above which the prevalence is less than $5 \%$. The black line is a trend line $(y=0.9702 \cdot x)$.

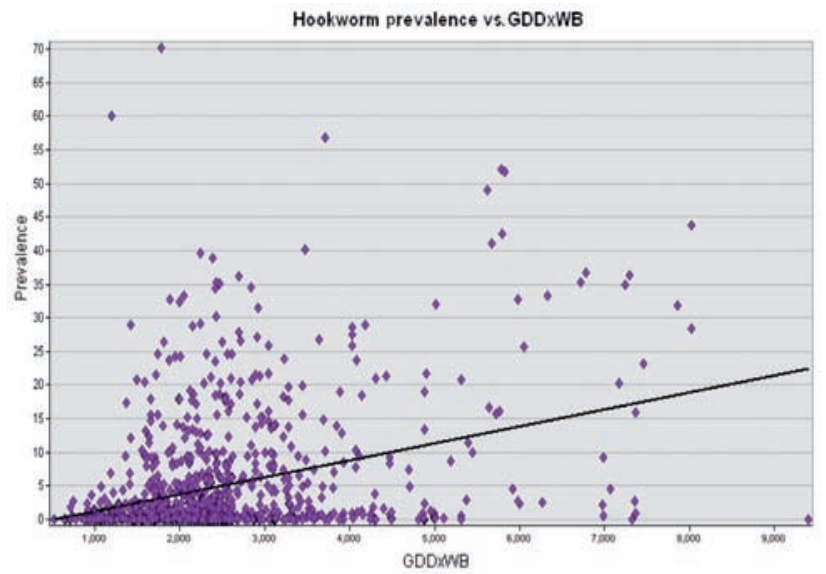

Fig. 4. Scatter plot of hookworm prevalence against the GDDxWB index. Prevalence levels increase dramatically above 1,300 with no obvious upper limit. The black line is a trend line $(\mathrm{y}=0.0031 \cdot \mathrm{x})$

Table 2. Literature reports (1990-2010) on hookworm prevalence in Brazil.

\begin{tabular}{|c|c|c|c|c|c|}
\hline No. & State & Location/municipality & $\begin{array}{l}\text { No. of people } \\
\text { examined }\end{array}$ & $\begin{array}{l}\text { Hookworm } \\
\text { prevalence }(\%)\end{array}$ & References \\
\hline 1 & Pernambuco & Sao Lourenco da Mata & 485 & 80.2 & Gonçalves et al., 1990 \\
\hline 2 & Rondônia & Porto Velho & 111 & 0.9 & Ferrari et al., 1992 \\
\hline 3 & Minas Gerais & Jaboticatubas & 512 & 10.0 & Cury et al., 1994 \\
\hline 4 & Sao Paulo & Sao Paolo & 407 & 0.0 & Ferreira et al., 1994 \\
\hline 5 & Mato Grosso & Pimentel Barbosa & 461 & 33.6 & Santos et al., 1995 \\
\hline 6 & Ceará & Fortaleza & 564 & 1.8 & Braga et al., 1998 \\
\hline 7 & Para & Paranatinga & 126 & 33.3 & Miranda et al., 1998 \\
\hline 8 & Para & Tomé-Açu & 93 & 29.0 & Miranda et al., 1999 \\
\hline 9 & Sergipe & Aracaju & 360 & 1.7 & Tsuyuoka et al., 1999 \\
\hline 10 & Goiás & & 138 & 18.1 & Cabral et al., 2000 \\
\hline 11 & Minas Gerais & Bambuí & 2,091 & 1.4 & Rocha et al., 2000 \\
\hline 12 & Paraná & Ortigueira & 100 & 52.0 & Scolari et al., 2000 \\
\hline 13 & Rio de Janeiro & Rio de Janeiro & 82 & 8.5 & Gomes et al., 2002 \\
\hline 14 & Piau & So Raimundo Nonato & 265 & 9.4 & Alves et al., 2003 \\
\hline 15 & Minas Gerais & Uberlandia & 78 & 6.4 & Oliveira et al., 2003 \\
\hline 16 & Minas Gerais & Arinos & 305 & 31.1 & Geiger et al., 2004 \\
\hline 17 & Ceará & Cascavel & 516 & 28.5 & Heukelbach et al., 2004 \\
\hline 18 & Bahia & Salvador & 1,893 & 14.4 & Moraes and Cairncross, 2004 \\
\hline 19 & Paraná & Jataizinho & 264 & 3.4 & Lopes et al., 2006 \\
\hline 20 & Mato Grosso do Sul & SidrolГndia & 313 & 7.0 & Aguiar et al., 2007 \\
\hline 21 & Minas Gerais & Americaninhas & 1,332 & 68.2 & Brooker et al., 2007 \\
\hline 22 & Paraná & Guarapuava & 631 & 1.7 & Buschini et al., 2007 \\
\hline 23 & Amazonas & Santa Isabel do Rio Negro & 307 & 13.1 & Carvalho-Costa et al., 2007 \\
\hline 24 & Bahia & Jequié & 13,279 & 8.6 & Silva et al., 2007 \\
\hline 25 & Acre & Acrelândia & 429 & 7.7 & Souza et al., 2007 \\
\hline 26 & Minas Gerais & Abadia dos Dourados & 376 & 17.8 & Machado et al., 2008a \\
\hline 27 & Minas Gerais & Uberlandia & 160 & 3.1 & Machado et al., 2008b \\
\hline 28 & Amazonas & Sáo Gabriel da Cachoeira & 333 & 75.0 & Bóia et al., 2009 \\
\hline 29 & Amazonas & Careiro & 54 & 20.4 & Melo et al., 2010 \\
\hline 30 & Minas Gerais & Patos of Minas & 161 & 22.0 & Silva and da Silva, 2010 \\
\hline
\end{tabular}




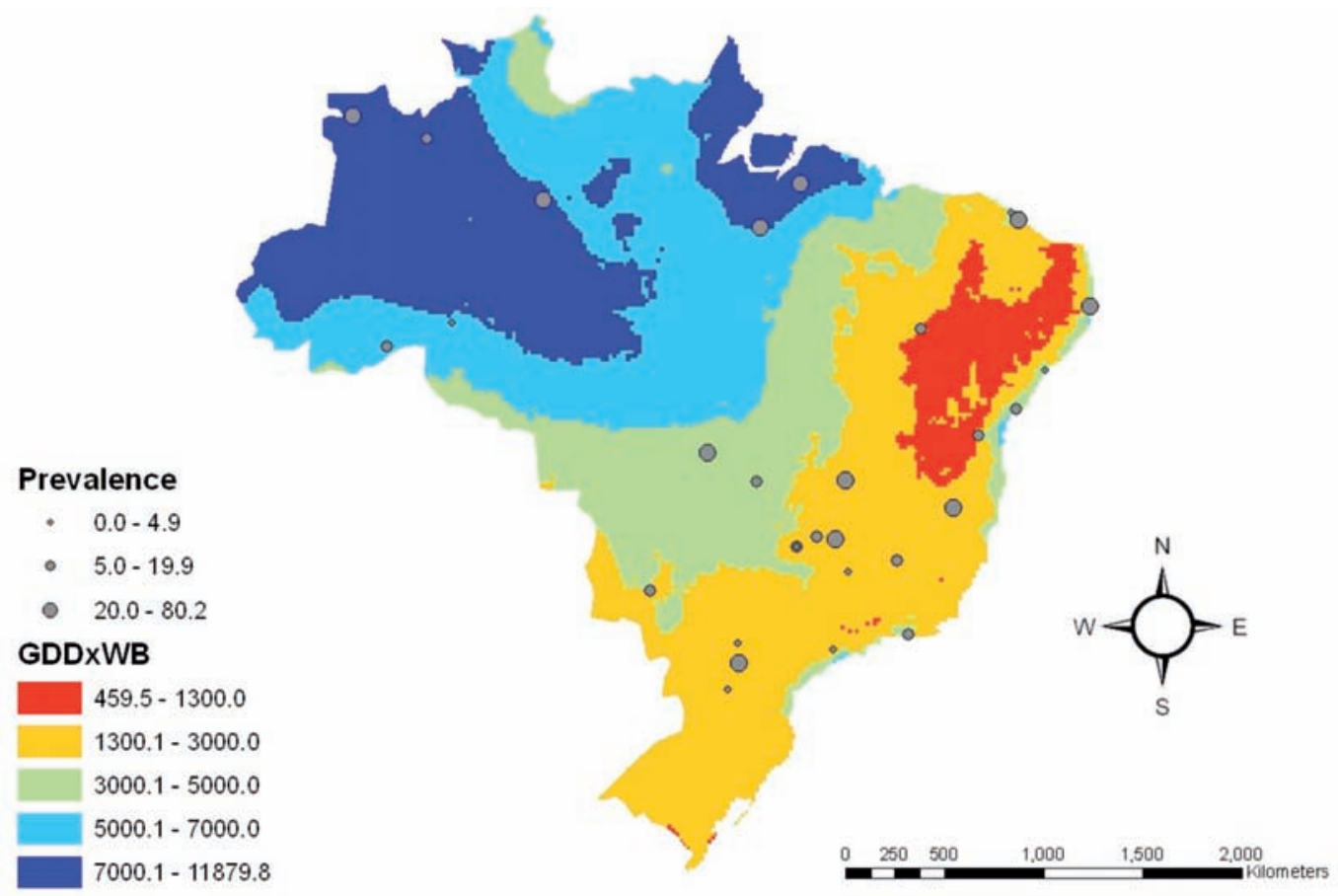

Fig. 5. Hookworm prevalence (graduated grey circles) from independent survey reports projected with the GDDxWB model. Low prevalence $(<5 \%)$ was seen in areas with low GDDxWB index of less than 1,300 (red).

one or more generations. The environmental temperature and moisture must be in a suitable range within the ecological niche of hookworms for the eggs to hatch and for the larvae to survive (Svensson, 1925; Udonsi and Atata, 1987). These conditions, correctly combined, contribute to propagation and transmission of the infection as long as there are susceptible definitive hosts in the vicinity. We developed and compared two models to evaluate geographic risk of hookworm infection based on climate, the MA-GDD and GDDxWB indices, using a LTN climate grid $(18 \times 18$ $\mathrm{km}$ ) of Brazil. These two models provide a method in which indicators of thermal-hydrology regime can be used to develop risk surfaces for hookworm based on climate and known biological requirements of the parasite. Both indices take into account environmental temperatures conducive to the development of the free living stages of the parasite as well as prevailing moisture conditions, although the MA-GDD index considers moisture above a given threshold of 0.4 and the GDDxWB index considers the entire range of a gradient of moisture.

\section{$M A-G D D$ index}

The MA-GDD index reflects suitable development days above the base temperature of $15^{\circ} \mathrm{C}$, wherefrom the number of "potential transmission cycles" that can be completed per year at a given $18 \times 18 \mathrm{~km}$ grid cell estimated from climate suitability parameters, can be calculated. Hookworm-infected individuals have been reported to shed eggs continuously for long periods of time, which under the right environmental conditions leads to development of infective larvae and potential year-round transmission. The developmental time of the hookworm from $\mathrm{L}_{3}$ to the egg producing adult in the host is fairly constant with a mean of eight weeks (Hoagland and Schad, 1978; Beaver, 1988). The variation in generation time (from egg to egg-producing adult) arises from the free-living stages of the parasite, here referred to as the mean transmission cycle period, which is highly susceptible to variation in environmental conditions. Because hookworms are highly dependent on moisture for their movement the annual GDD was adjusted according to ground moisture (MA-GDD) to exclude months where the mean water budget was less than 0.4. This threshold was based on the prevalence data recorded in 2000-2009 from 980 municipalities in areas endemic for schistosomiasis, which indicated that the prevalence of hookworm was less than $5 \%$ in municipalities where the mean annual water budget was less than 0.4 . This result suggests that infective larval transmission is impaired as the soils get drier (Nwosu and Anya, 1980; Udonsi and 
Atata, 1987). Since the GDD from those months do not contribute to the annual accumulated GDD, dry months were thus not included in the index calculations.

Evidence from literature reports indicate that the time from egg to infective larval development can be up to 14 days at temperatures less than $40{ }^{\circ} \mathrm{C}(\mathrm{Schad}$ and Warren, 1990; Brooker et al., 2006b), and the period of time that the majority of infective larvae remain active in the environment ranges from one to four weeks (Svensson, 1925; Beaver, 1953; Udonsi, 1988). Therefore, considering two weeks for development to the infective $\mathrm{L}_{3}$ stage and two weeks longevity (on average) for infective larvae in which they must find a definitive host, the generation time was estimated to be four weeks. This criterion was used as an indicator of biological suitability of different climate thermal-hydrological regimes for the purposes of this study. However, depending on the basis for calculation, which references are used, as well as ease of access to a host, the transmission time can potentially range from nine days as reported by Palmer and Reeder (2001) if infection occurs immediately after molting to $\mathrm{L}_{3}$, to approximately 51 days (Svensson, 1925; Udonsi, 1988; Palmer and Reeder, 2001), if the larvae survive in the environment. Our estimation of the generation time takes into account factors that may delay the embryonation and hatching of eggs, for example low temperature and the reported period the $\mathrm{L}_{3}$ larvae are active in the environment prior to infection (Table 3). The use of the estimated generation cycle time parameter is proposed to provide a biologybased criterion for regional risk modelling based on the GDD-WB concept.

In comparison to $N$. americanus, hypobiosis (interruption of the continuous shedding of eggs) of $A$. duodenale in the human host has been described as a important part of its strategy in adjusting to environmental stress in temperate and sub-tropical regions (Nawalinski and Schad, 1974). Because it is not the predominant species in Brazil, A. duodenale was not considered in the models developed in the present study. Hypobiosis, has not been demonstrated in N. americanus (Loukas and Prociv, 2001) and it is possible to use the number of mean transmission cycles per year for describing its distribution and generating risk map surfaces based on long-lived adult worm populations.

Using the MA-GDD model, we found that most areas with a prevalence of above $5 \%$ had index values between 1,500 and 3,000, allowing 5-14 mean transmission cycles per year (Fig. 3). The Caatinga ecological zone presents index values below this range, while regions with the highest MA-GDD index values are found in the Amazon region, the northern coast area and the Bahia coastal forests, which are characterized by moist broadleaf forests. Infective larvae do not survive well in water without some kind of substrate (Schad and Warren, 1990) and results suggest that the larvae may not survive long where there is frequent flooding and run-off such as in the Bahia coastal forests. However, early and also more recent literature reports suggest the Amazon region has a high prevalence of indigenous populations (Chandler, 1929; Botero, 1981; Miranda et al., 1998; Bóia et al., 2009). A comparison between the MA-GDD index and the categories of low, moderate and high hookworm prevalence revealed that there was a significant difference (Student t-test) in MA-GDD, means between the low prevalence and the moderate and high prevalence categories. However, a significant level of heterogeneity was observed in the distribution of hookworm in areas classified as moderate or high prevalence with over five potential transmission cycles per year.

Table 3. Important biological and climatic variables for the transmission of N. americanus used as baseline values for calculations based on the GDD-WB concept.

\begin{tabular}{lll}
\hline Variables & Value & References \\
\hline Base temperature & $15{ }^{\circ} \mathrm{C}$ & Udonsi and Atata, 1987 \\
Mean annual temperature & $23{ }^{\circ} \mathrm{C}$ & From Brazil climate data \\
Daily GDD & 8 & This study \\
Mean annual potential GDD & 2970.5 & This study \\
Mean transmission cycle time (free-living phase) & 28 days (range 9-51) & Beaver, 1953; Croll and Matthews, 1973; Udonsi and Atata, \\
& & 1987; Udonsi, 1988; Palmer and Reeder, 2001 \\
Transmission cycle GDDs & 224 & This study \\
Mean egg life expectancy & $13-14$ days & Schad and Warren, 1990 \\
Adult life span & $3-4$ years & Schad and Warren, 1990 \\
\hline
\end{tabular}




\section{GDDxWB index}

In contrast to the MA-GDD index, the GDDxWB index did not have an upper cut-off point (i.e. maximum of 14 transmission cycles per year for MA-GDD) for hookworm prevalence (Fig. 4), and there was a statistically significant distinction (Student t-test) between areas of low, moderate and high prevalence of hookworm with respect to the GDDxWB index. The low prevalence areas had a GDDxWB index of less than 1,300, moderate areas ranged between 1,300 and 7,300, while high prevalence areas had values in excess of 7,300 . The moderate prevalence regions again included some high prevalence points, showing that some individual sites present the potential for high rates of hookworm transmission. Although an individual site may be in a climate "permissive" regional zone, it is typical to observe considerable variation in actual versus potential transmission levels at individual sites, even in high risk climates, because of location-specific factors related to poverty, occupational-agricultural practices or local environment, such as location along rivers or wetland plains. Climate risk is therefore an indicator of potential transmission related to mean transmission of individual sites in a broader regional climatic envelope (Malone, 2005). The GDDxWB index provides the advantage of measuring a moisture availability gradient of suitability but not the number of transmission cycles per year.

In risk maps, based on both the MA-GDD and GDDxWB indices, results suggest that the low temperature (mean temperatures less than $21^{\circ} \mathrm{C}$ ) is the factor inhibiting hookworm transmission in southern Brazil as the climate in this region is much cooler, with minimum temperatures commonly falling below the base temperature $\left(15^{\circ} \mathrm{C}\right)$ for hatching of hookworm eggs (Schad and Warren, 1990). The GDDxWB index model had a significantly higher correlation coefficient for hookworm prevalence as compared to the MAGDD index $(0.38$ versus 0.25$)$. This may be due to the fact that the latter index did not have a completely linear relationship with hookworm prevalence, having an upper end cut-off (3,000 MA-GDD; 14 transmission cycles per year) beyond which the prevalence dropped to less than $5 \%$ (Fig. 3). The majority of the points with over 14 transmission cycles per year are in the very moist coastal forest of Bahia where runoff could contribute to the low prevalence.

Although there were 980 municipality points to consider and the Kato-Katz method was used (Machado, 1982), it was not defined how standardized the meth- ods of surveillance were in terms of numbers and ages of people examined. The most ideal would have been regular surveillance of schoolchildren as recommended by WHO and the Brazilian SCP (Machado, 1982), in which an average of about $30 \%$ of the population would be examined when exceeding 100. However, from the numbers of people examined, it was thought not to be the case followed in data collection, especially in municipalities where very low numbers of people were examined, in which case the proportion of the population found to be positive would most probably not be representative of the population in the municipality. Hence, we adopted the criterion of exclusion of data points with less than 100 people examined.

\section{Data validation}

From the independent surveys reported in literature that were used to validate the models, the majority of the points fit better in the GDDxWB model (Fig. 5) than in the MA-GDD model, suggesting that there is no upper limit to the thermal hydrologic index with regard to hookworm transmission in Brazil. Findings from the 30 site surveys indicate high prevalence of hookworm in the Amazon basin, which is consistent with assumptions by Chandler (1929) as well as predictions by our GDDxWB model. According to early studies by the Department of the Rural Endemic Diseases (Departmento Nacional de Endemias Rurais, 1962) hookworm does occur in most of the country, including the Amazon region but has lower prevalence in the drier areas of the northeastern part of the country. A limitation in the validation database was the availability of only 30 data points, all of which lay outside the Caatinga. Provision of water at the microenvironment level through human activities, e.g. the sugar plantations in Sao Lourenco da Mata, Pernambuco, which had a prevalence of $80 \%$ (Gonçalves et al., 1990), facilitates the creation of an ideal hookworm environment. In order to further validate the models produced, a comprehensive national survey for STHs is needed, since hookworm often is found together with other STHs (Fleming et al., 2006). This should include areas of limited surveillance for schistosomiasis such as in the Amazon basin and the Caatinga areas.

Other environmental variables, identified in the literature as important for hookworm transmission and propagation, include soil type, slope, altitude and land surface temperature measurements derived from satellites (Udonsi et al., 1980; Mabaso et al., 2003; Brooker et al., 2006b). The areas on the northeastern coast line of Brazil showed high hookworm preva- 
lence, a finding similar to that reported by Mabaso et al. (2003) who found that the soils were sandy loam and conducive for vertical migration of hookworm larvae (Payne, 1923; Udonsi, 1988). Soil texture has a strong association with soil moisture content (Payne, 1923), which has been shown to possess a positive linear correlation with hookworm infection levels (Nwosu and Anya, 1980). Socio-economic status has long been recognized as an important variable relating to parasitic infections, including hookworm (Hotez, 2008; Salahi-Moghaddam et al., 2010). Several studies have shown a similar trend in Brazil (Kobayashi et al., 1995; Fleming et al., 2006; Brooker et al., 2007). As this was a climate-based model, it did not take into account other factors relating to the prevalence of hookworm and future studies should be directed towards investigating these factors.

Vegetation cover or shade have been shown to be important for the longevity of hookworm larvae (Udonsi and Atata, 1987). The models produced in the current study show low risk in forested areas such as the Bahia coastal forest, which has similar ecological characteristics to the vegetation of the Amazon basin. Other factors such as deforestation in areas where humans live or better sanitary practices may account for this difference. Addictional surveys are necessary to further refine the effect of climate alone and to validate the influence of these factors.

\section{Conclusions}

The prevalence of hookworm in Brazil appears to be strongly related to both warmer and moister climatic conditions where the GDDxWB index is above 1,300 and where the MA-GDD index dictates a minimum number of five transmission cycles per year.

Low prevalence is predicted in arid areas, e.g. the Caatinga with GDDxWB $<1,300$ and a number of potential transmission cycles less than five, or areas characterized mean monthly temperatures below $21{ }^{\circ} \mathrm{C}$ as for example seen in the areas south of Sao Paulo. This study supports the validity of the GDD-WB concept for use in mapping risk areas for hookworm.

There is need for a systematic national survey for hookworm and other STHs in Brazil to elucidate STH disease risk outside the schistosomiasis endemic areas where limited surveillance exists.

\section{Acknowledgements}

We are grateful to the Pan-American Health Organization for funding this study. We also gratefully acknowledge support pro- vided through the Fulbright Foreign Student Program to Ntombi Mudenda.

\section{References}

Aguiar JIA, Gonçalves AQ, Sodré FC, Pereira SdR, Bóia MN, Lemos ERSd, Daher RR, 2007. Intestinal protozoa and helminths among Terena Indians in the state of Mato Grosso do Sul: high prevalence of Blastocystis hominis. Rev Soc Bras Med Trop 40, 631-634.

Alves JR, Macedo HW, Ramos Jr. AN, Ferreira LF, Gonçalves MLC, Araújo A, 2003. Parasitoses intestinais em região semiárida do Nordeste do Brasil: resultados preliminares distintos das prevalências esperadas. Cad Saude Publica 19, 667-670.

Amaral RSd, Tauil PL, Lima DD, Engels D, 2006. An analysis of the impact of the Schistosomiasis Control Programme in Brazil. Mem Inst Oswaldo Cruz 101, 79-85.

Andrewartha HG, Birch LC, 1954. The distribution and abundance of animals, University of Chicago Press, Chicago, 3-12 pp. Beaver PC, 1953. Persistence of hookworm larvae in soil. Am J Trop Med Hyg 2, 102-108.

Beaver PC, 1988. Light, long-lasting Necator infection in a volunteer. Am J Trop Med Hyg 39, 369-372.

Bergquist R, Rinaldi L, 2010. Health research based on geospatial tools: a timely approach in a changing environment. J Helminthol 84, 1-11.

Bóia MN, Carvalho-Costa FA, Sodré FC, Porras-Pedroza BE, Faria EC, Magalhães GAP, Silva IMd, 2009. Tuberculose e parasitismo intestinal em população indígena na Amazônia brasileira. Rev Saude Publica 43, 176-178.

Booth M, Bundy DAP, 1992. Comparative prevalences of Ascaris lumbricoides, Trichuris trichiura and hookworm infections and the prospects for combined control. Parasitology 105, 151-157.

Booth M, Vounatsou P, N'Goran EK, Tanner M, Utzinger J, 2003. The influence of sampling effort and the performance of the Kato-Katz technique in diagnosing Schistosoma mansoni and hookworm co-infections in rural Côte d'Ivoire. Parasitology 127, 525-531.

Botero D, 1981. Persistence of the intestinal parasites endemic in Latin America. Rev Panam Salud Publica 15, 241-248.

Braga LL, Mendonca Y, Paiva CA, Sales A, Cavalcante ALM, Mann BJ, 1998. Seropositivity for and intestinal colonization with Entamoeba histolytica and Entamoeba dispar in individuals in northeastern Brazil. J Clin Microbiol 36, 3044-3045.

Brooker S, Clements A, Hotez P, Hay S, Tatem A, Bundy D, Snow R, 2006a. The co-distribution of Plasmodium falciparum and hookworm among African schoolchildren. Malaria J 5, 99.

Brooker S, Clements ACA, Bundy DAP, 2006b. Global epidemiology, ecology and control of soil-transmitted helminth infections. Adv Parasitol 62, 221-261. 
Brooker S, Jardim-Botelho A, Quinnell RJ, Geiger SM, Caldas IR, Fleming F, Hotez PJ, Correa-Oliveira R, Rodrigues LC, Bethony JM, 2007. Age-related changes in hookworm infection, anaemia and iron deficiency in an area of high Necator americanus hookworm transmission in south-eastern Brazil. Trans R Soc Trop Med Hyg 101, 146-154.

Buschini MLT, Pittner E, Czervinski T, Moraes IdF, Moreira MM, Sanches HF, Monteiro MC, 2007. Spatial distribution of enteroparasites among school children from Guarapuava, state of Paraná, Brazil. Rev Bras Epidemiol 10, 568-578.

Cabral DD, Mundim MJS, Oliveira PRd, Santos SdFO, Gomes SM, 2000. Intestinal parasitoses in school children from Gouvelândia, Goiás State. J Bioscience 16, 75-85.

Carvalho-Costa FA, Gonçalves AQ, Lassance SL, Silva Neto LMd, Salmazo CAA, Bóia MN, 2007. Giardia lamblia and other intestinal parasitic infections and their relationships with nutritional status in children in Brazilian Amazon. Rev Inst Med Trop São Paolo 49, 147-153.

Chandler AC, 1929. Hookworm disease. Macmillan Company, New York, USA.

Corbett JD, 2005. South America minimum medical GIS database. Malone JB, Wiles SE, Nieto P, McCarroll JC, Bavia M, (eds).

Croll NA, Matthews BE, 1973. Activity, ageing and penetration of hookworm larvae. Parasitology 66, 279-289.

Cury GC, Salles PG, Reis MC, Rego VM, Arndt AW, de Souza Filho CB, Moreira HB, de Abreu MS, Leite PM, 1994. Prevalence of Schistosoma mansoni and parasitic intestinal diseases among students of the rural area of the municipality of Jaboticatubas, MG, 1992-1993. Rev Soc Bras Med Trop 27, 217-220.

Departmento Nacional de Endemias Rurais, 1962. Combate a endemias rurais no Brasil, Ministero da Saude.

Dutra LH, Molento MB, Naumann CRC, Biondo AW, Fortes FS, Savio D, Malone JB, 2010. Mapping risk of bovine fasciolosis in the south of Brazil using geographic information systems. Vet Parasitol 169, 76-81.

FAO, 2001. Global ecological zoning for the global forest resources assessment 2000 (Rome), pp. 91-105.

Ferrari JO, Ferreira MU, Aranha Camargo LM, Ferreira CS, 1992. Intestinal parasites among Karitiana indians from Rondônia State, Brazil. Rev Inst Med Trop São Paolo 34, 223 225.

Ferreira CS, Ferreira MU, Nogueira MR, 1994. The prevalence of infection by intestinal parasites in an urban slum in Sao Paulo, Brazil. J Trop Med Hyg 97, 121-127.

Fleming FM, Brooker S, Geiger SM, Caldas IR, Correa-Oliveira R, Hotez PJ, Bethony JM, 2006. Synergistic associations between hookworm and other helminth species in a rural community in Brazil. Trop Med Int Health 11, 56-64.

Fuentes MV, Sainz-Elipe S, Nieto P, Malone JB, Mas-Coma S, 2005. Geographical information systems risk assessment mod- els for zoonotic fascioliasis in the South American Andes region. Parassitologia 47, 151-156.

Geiger SM, Massara CL, Bethony J, Soboslay PT, CorrêaOliveira R, 2004. Cellular responses and cytokine production in post-treatment hookworm patients from an endemic area in Brazil. Clin Exp Immunol 136, 334-340.

Gomes TC, Almeida MF, Miura LA, Granja J, Santos DVG, Oliveira RMF, Lopes A, Sequeira BP, Rolemberg AA, Moraes AL, Santos CS, 2002. Helmintoses intestinais em população de rua da cidade do Rio de Janeiro. Rev Soc Bras Med Trop 35, 531-532.

Gonçalves JF, Tanabe M, Medeiros FdPdM, Gonçalves FJ, Aca IdS, Motta SRNd, Tateno S, Takeuchi T, 1990. Parasitological and serological studies on amoebiasis and other intestinal parasitic infections in the rural sector around Recife, Northeast Brazil. Rev Inst Med Trop São Paolo 32, 428-435.

Heukelbach J, Winter B, Wilcke T, Muehlen M, Albrecht S, Oliveira FASd, Kerr-Pontes LRS, Liesenfeld O, Feldmeier H, 2004. Selective mass treatment with ivermectin to control intestinal helminthiases and parasitic skin diseases in a severely affected population. Bull World Health Organ 82, 563-571. Hoagland KE, Schad GA, 1978. Necator americanus and Ancylostoma duodenale: life history parameters and epidemiological implications of two sympatric hookworms of humans. Exp Parasitol 44, 36-49.

Hotez P, 2008. Hookworm and poverty. Ann NY Acad Sci 1136, 38-44.

Katz N, Chaves A, Pellegrino J, 1972. A simple device for quantitative stool thick-smear technique in schistosomiasis mansoni. Rev Inst Med Trop São Paolo 14, 387-400.

Kobayashi J, Hasegawa H, Forli AA, Nishimura NF, Yamanaka A, Shimabukuro T, Sato Y, 1995. Prevalence of intestinal parasitic infection in five farms in Holambra, São Paulo, Brazil. Rev Inst Med Trop São Paolo 37, 13-18.

Lindsay SW, Thomas CJ, 1999. Mapping and estimating the population at risk from lymphatic filariasis in Africa. Trans $\mathrm{R}$ Soc Trop Med Hyg 94, 37-45.

Lopes FMR, Gonçalves DD, dos Reis CR, Breganó RM, Filho FA, Murad VA, Dutra de Menezes MCN, Freire RL, de Freitas JC, Santana MAZ, 2006. Occurrence of enteroparasitosis in schoolchildren of the municipal district of Jataizinho, state of Paraná, Brazil. Acta Sci Health 28, 107-111.

Loukas A, Prociv P, 2001. Immune responses in hookworm infections. Clin Microbiol Rev 14, 689-703.

Mabaso MLH, Appleton CC, Hughes JC, Gouws E, 2003. The effect of soil type and climate on hookworm (Necator americanus) distribution in KwaZulu-Natal, South Africa. Trop Med Int Health 8, 722-727.

Machado ER, de Souza TS, da Costa JM, Costa-Cruz JM, 2008a. Enteroparasites and commensals among individuals living in rural and urban areas in Abadia dos Dourados, Minas Gerais state, Brazil. Parasitologia Latinoamericana 63, 34-39. 
Machado ER, Santos DS, Costa-Cruz JM, 2008b. Enteroparasites and commensals among children in four peripheral districts of Uberlândia, state of Minas Gerais. Rev Soc Bras Med Trop 41, 581-585.

Machado PA, 1982. The Brazilian program for schistosomiasis control, 1975-1979. Am J Trop Med Hyg 31, 76-86.

Malone JB, 2005. Biology-based mapping of vector-borne diseases by geographic information systems and remote sensing. Parasitologia 47, 27-50.

Malone JB, McCarroll JC, Wiles SE 2007a. Geospatial health and environment: a lessons manual and CD-Rom Data Resource, Louisiana State University, Baton Rouge, USA.

Malone JB, Seklau EW, McCarroll JC, Bavia M 2007b. South American region minimum medical GIS database.

Malone JB, Williams TE, Muller RA, Greghen JP, Loyeceno AF, 1987. Fascioliasis in cattle in Louisiana: development of a system to predict disease risk by climate, using the Thornthwaite water budget. Am J Vet Res 48, 1167-1170.

Malone JB, Yilma JM, McCarroll JC, Erko B, Mukaratirwa S, Zhou X, 2001. Satellite climatology and the environmental risk of Schistosoma mansoni in Ethiopia and East Africa. Acta Trop 79, 59-72.

Melo GC, Reyes-Lecca RC, Vitor-Silva S, Monteiro WM, Martins M, Benzecry SG, Alecrim MdGC, Lacerda MVG, 2010. Concurrent helminthic infection protects schoolchildren with Plasmodium vivax from anemia. PLoS One 5, e11206.

Miranda RA, Xavier FB, Menezes RC, 1998. Intestinal parasitism in a Parakanã indigenous community in southwestern Pará State, Brazil. Cad Saude Publica 14, 507-511.

Miranda RA, Xavier FB, Nascimento JR, de Menezes RC, 1999. The prevalence of intestinal parasitism in native villages of the Tembé tribe, the Brazilian eastern Amazon. Rev Soc Bras Med Trop 32, 389-393.

Moraes LRS, Cairncross S, 2004. Environmental interventions and the pattern of geohelminth infections in Salvador, Brazil. Parasitology 129, 223-232.

Nawalinski TA, Schad GA, 1974. Arrested development in Ancylostoma duodenale: course of a self-induced infection in man. Am J Trop Med Hyg 23, 895-898.

Nieto P, Malone JB, Bavia ME, 2006. Ecological niche modeling for visceral leishmaniasis in the state of Bahia, Brazil, using genetic algorithm for rule-set prediction and growing degree day-water budget analysis. Geospat Health 1, 115-126.

Nwosu ABC, Anya AO, 1980. Seasonality in human hookworm infection in an endemic area of Nigeria, and its relationship to rainfall. Tropenmed Parasitol 31, 201-208.

Oliveira MC, Silva CVd, Costa-Cruz JM, 2003. Intestinal parasites and commensals among individuals from a landless camping in the rural area of Uberlândia, Minas Gerais, Brazil. Rev Inst Med Trop São Paolo 45, 173-176.

Palmer PES, Reeder MM 2001. Imaging of tropical diseases: with epidemiological, pathological and clinical correlation.
Springer-Verlag, Berlin, Germany, pp. 52-65.

Payne FK, 1923. Investigations on the control of hookworm disease: studies on factors involved in migration of hookworm larvae in soil. Am J Epidemiol 3, 547-583.

Raso G, Vounatsou P, Gosoniu L, Tanner M, N'Goran EK, Utzinger J, 2006. Risk factors and spatial patterns of hookworm infection among schoolchildren in a rural area of western Côte d'Ivoire. Int J Parasitol 36, 201-210.

Rocha RS, Silva JG, Peixoto SV, Caldeira RL, Firmo JO, Carvalho O dos S, Katz N, 2000. Assessment of schistosomiasis and other intestinal parasitoses in school children of the Bambuí municipality, Minas Gerais, Brazil. Rev Soc Bras Med Trop 33, 431-436.

Salahi-Moghaddam A, Mohebali M, Moshfae A, Majid H, Zarei Z, 2010. Ecological study and risk mapping of visceral leishmaniasis in an endemic area of Iran based on a geographical information systems approach. Geospat Health 5, 71-77. Santos RV, Coimbra Júnior CE, Flowers NM, Silva JP, 1995. Intestinal parasitism in the Xavánte Indians, central Brazil. Rev Inst Med Trop São Paolo 37, 145-148.

Schad GA, Warren KS 1990. Hookworm disease, current status and new directions. Taylor and Francis, London, 71-102 pp.

Scolari C, Torti C, Beltrame A, Matteelli A, Castelli F, Gulletta M, Ribas M, Morana S, Urbani C, 2000. Prevalence and distribution of soil-transmitted helminth (STH) infections in urban and indigenous schoolchildren in Ortigueira, State of Paranà, Brazil: implications for control. Trop Med Int Health 5, 302-307.

Silva LP, da Silva RMG, 2010. Occurence of enteroparasites in centers education child of the municipality of Patos of Minas, MG, Brazil. J Bioscience 26, 147-151.

Silva RdCR, Barreto ML, Assis AMO, de Santana MLP, Parraga IM, Reis MG, Blanton RE, 2007. The relative influence of polyparasitism, environment, and host factors on schistosome infection. Am J Trop Med Hyg 77, 672-675.

Souza EAd, Silva-Nunes Md, Malafronte RdS, Muniz PT, Cardoso MA, Ferreira MU, 2007. Prevalence and spatial distribution of intestinal parasitic infections in a rural Amazonian settlement, Acre State, Brazil. Cad Saude Publica 23, 427-434. Stoltzfus RJ, Albonico M, Chwaya HM, Savioli L, Tielsch J, Schulze K, Yip R, 1996. Hemoquant determination of hookworm-related blood loss and its role in iron deficiency in African children. Am J Trop Med Hyg 55, 399-404.

Svensson R, 1925. Observations on the development and longevity of hookworm larvae in different temperature conditions. Chin Med J 39, 667-673.

Thomson MC, Connor SJ, Milligan P, Flasse SP, 1997. Mapping malaria risk in Africa: what can satellite data contribute? Parasitol Today 13, 313-318.

Tsuyuoka R, Bailey JW, Guimarães AMdAN, Gurgel RQ, Cuevas LE, 1999. Anemia and intestinal parasitic infections in primary school students in Aracaju, Sergipe, Brazil. Cad Saude 
Publica 15, 413-421.

Udonsi JK, 1988. Experimental and field studies on the viability of eggs, and the infectivity of third-stage larvae of the human hookworm Necator americanus recovered from the creek waters of the Niger Delta, Nigeria, and their epidemiological significance. Parasitology 96, 111-117.

Udonsi JK, Atata G, 1987. Necator americanus: temperature, $\mathrm{pH}$, light, and larval development, longevity, and desiccation tolerance. Exp Parasitol 63, 136-142.

Udonsi JK, Nwosu ABC, Anya AO, 1980. Necator americanus: population structure, distribution, and fluctuations in population densities of infective larvae in contaminated farmlands. Parasitol Res 63, 251-259.
Valencia-López N, Malone JB, Velásquez LE, Carmona CG, 2012. Climate-based risk models for Fasciola hepatica in Colombia. Geospat Health 6, S75-S85.

WHO, 2011. Initiative for vaccine research: parasitic diseases. Yang GJ, Gao Q, Zhou SS, Malone JB, McCarroll JC, Vounatsou P, Bergquist R, Utzinger J, Zhou XN, 2010. Mapping and predicting malaria transmission in the People's Republic of China, using integrated biology-driven and statistical models. Geospat Health 5, 11-22.

Zhou XN, Malone JB, Kristensen TK, Bergquist NR, 2001. Application of geographic information systems and remote sensing to schistosomiasis control in China. Acta Trop 79, 97-106. 